\title{
LA UNIVERSALIDAD Y SUS CIRCUNSTANCIAS: TRES DIALÉCTICAS MAULINAS
}

\author{
Universality and Its Circumstances: Three Dialectics from the Maule Region
}

\author{
Glenn Deulofeu*
}

\begin{abstract}
RESUMEN
El texto indaga en la dialéctica entre las vertientes universales y circunstanciales que nutren gran parte de la producción arquitectónica moderna. En vez de generar definiciones específicas para un modo de construir dentro de cierto territorio, los tres casos aquí presentados ejemplifican una manera más amplia de concebir el proyecto de arquitectura, cuya flexibilidad, apertura y adaptabilidad se hizo extensible hasta zonas periféricas como la Región del Maule, en Chile. La identidad formal de estas obras y sus relaciones de pertenencia con el medio, se fraguan caso a caso, incorporando en sus síntesis los necesarios modelos universales de orden -connaturales a los sistemas constructivos y sus materialesy los aspectos circunstanciales del programa, los lugares, el momento y los arquitectos respectivos. Junto con hacer hincapié en el análisis fotográfico y planimétrico de cada una de las obras, se ha pretendido ofrecer también una aproximación al contexto histórico y teórico al que estas producciones están directa o indirectamente ligadas.
\end{abstract}

Palabras clave: arquitectura moderna, forma moderna, edificación, Región del Maule.

\footnotetext{
* Escuela de Arquitectura, Facultad de Arquitectura, Música y Diseño, Universidad de Talca. Talca, Chile. Correo electrónico: gdeulofeu@utalca.cl

Artículo recibido el 19 de mayo de 2016. Aceptado el 25 de septiembre de 2017.
} 


\begin{abstract}
The text explores the dialectics between the universal and circumstantial sources that nourish a great part of the modern architectural production. Instead of generating specific definitions for a way of building within a certain territory, the three cases here presented exemplify a broader way to conceive the architectural project, whose flexibility, openness and adaptability stretched into the outlying areas of the Maule Region, in Chile. The formal identity of these works and their relationships of belonging to the environment are settled case by case, incorporating in their synthesis the necessary universal models of order -connatural to the building systems and their materials- and the circumstantial aspects of the program, the places, the time and the architects involved. Along with highlighting the photographic and planimetric analysis of each of the works, the intention is also to provide an approximation to the historical and theoretical context to which these productions are linked, directly or indirectly.
\end{abstract}

Keywords: Modern architecture, modern form, building, Maule Region.

En el Valle Central de Chile, zona que se suele asociar con imágenes de la cultura agraria, se emplazan ciertas obras de arquitectura de características abstractas, que llevan más de medio siglo formando parte de la cotidianidad del marco urbano, raigambre fortalecida al parecer por una profunda trama de vínculos formales. En Talca y Linares, ciudades cercanas al río Maule, podemos encontrar estas singulares obras, configuradas en gran medida por la tensión entre las variables universales y circunstanciales en las que ineludiblemente se han visto envueltas. Más allá de asignarles etiquetas tentativas y quizá pertinentes -como la de regionalismo crítico, por ejemplo-, interesa aquí pensar sus cualidades a la luz de los procesos lógicos de proyecto y de construcción, apriorismos objetivos desde los cuales ha sido posible alcanzar resultados de apreciable calidad y condición estética.

\title{
LA UNIVERSALIDAD DE LA FORMA
}

Se podría decir que una parte importante de la modernidad está enraizada en una noción de universalidad que se comienza a hacer patente a partir del desarrollo del conocimiento científico y que eclosiona con productos materiales en el periodo conocido como Revolución Industrial. Este periodo estimula vigorosamente el advenimiento de una apreciación estética que repara en los esquemas de órdenes esenciales - "las leyes" según Ozenfant y Le Corbusier (1994, p. 29)- por sobre la apariencia natural y figurativa de las formas y las cosas. En un principio, la forma universal, por su afinidad con las leyes de la física, se tiende a plasmar en las obras 
de ingeniería de finales del siglo XVIII. Con la construcción entre 1775 y 1779 del puente sobre el río Severn en Inglaterra, el primero construido en hierro fundido (Giedion, 2009, p. 192), se da inicio a un proceso evolutivo que seguiría con la búsqueda de ligereza, economía y precisión estructural en la construcción de los invernaderos parisinos, alcanzando estos una dimensión social y colosal en el Crystal Palace de Londres, de 1851.

Paralelamente, la influencia que las fábricas y silos norteamericanos del siglo XIX ejercen en Walter Gropius para la realización de la Fábrica Fagus en 1913 (Giedion, 2009, p. 348), junto con el fuerte impacto que causa en Mies van der Rohe la exposición sobre Frank Lloyd Wright realizada en Berlín hacia 1910 (Giedion, 2009, p. 70), marcan una significativa transferencia de imágenes de modernidad desde Norteamérica hacia Europa. Con estas figuras y con la creación de la Bauhaus en 1919, Alemania se transforma en el principal centro de experimentación de la forma moderna, aunque considerando, eso sí, el influjo fundamental de las vanguardias pictóricas que provienen de Rusia, personificadas en Kandinsky, así como de Holanda, personificadas en Theo van Doesburg (Frampton, 2014, pp. 127-128).

A grandes rasgos y luego de muchos intentos, este proceso cristaliza maduro y convincente con la construcción entre 1928 y 1930 de la Villa Saboya en Poissy, Francia, a cargo de Le Corbusier, y con la construcción del Pabellón Alemán para la Exposición Universal de Barcelona en 1929, por parte de Mies van der Rohe. La arquitectura moderna deja de entenderse solamente como formas puras y racionales, pasando a constituir un nuevo tipo de riqueza formal apto para la vida de los nuevos tiempos, en tanto que sistemas constructivos adintelados que favorecen la interrelación simultánea entre el interior y el exterior (NorbergSchulz, 2005, p. 46), a la vez que amplían exponencialmente las posibilidades de configuración de los elementos de cerramiento, esta vez totalmente independientes de los elementos portantes.

Durante los ańos previos a la Segunda Guerra Mundial, Le Corbusier realiza algunos viajes a Sudamérica, los que dejan aquí una decisiva huella. Su asesoría para el equipo en el cual participa el joven Oscar Niemeyer y que por entonces se encuentra desarrollando el Edificio para el Ministerio de Educación y Salud de Río de Janeiro, construido entre los años 1937-43, desemboca en una arquitectura donde "buena parte de las imágenes arquitectónicas tienen un preciso origen corbuseriano" (Bullrich, 1969, p. 20). A partir de la posguerra y hasta mediados de los años sesenta, la arquitectura moderna sudamericana exhibe un destacado desarrollo, aportando renovación al repertorio mundial. En ello sobresale especialmente el brasilero Niemeyer, quien lograría caracterizar a la arquitectura de su país "liberándose del ortogonalismo purista" (Bullrich, 1969, p. 21).

En este contexto surge también el aporte de la arquitectura moderna chilena, que a pesar de las pequeńas dimensiones del país, destaca "por la inteligente acción 
llevada a cabo en el campo de la vivienda de interés social" (Bullrich, 1969, p. 70), y por el Edificio Cepal de 1966, proyectado por Emilio Duhart, discípulo de Gropius y colaborador en el taller de Le Corbusier durante 1952 (Bullrich, 1969, p. 67).

\section{LAS CIRCUNSTANCIAS DEL PROYECTO}

"Aunque pueda parecer paradójico, la universalidad de los valores básicos de la forma es la condición que garantiza lo específico de sus manifestaciones particulares", sugiere Helio Piñón (2006, p. 52). En efecto, aquella universalidad incubada a principios del siglo XX incorpora los aspectos particulares y circunstanciales de las obras a partir de estructuras formales universales que actúan como marcos abiertos, capaces de asimilar tanto las características del predio como todo lo relativo al entorno inmediato, el asoleamiento, los requerimientos funcionales, las técnicas disponibles, la capacidad presupuestaria, las restricciones normativas, las exigencias del propietario y, en suma, el programa del edificio, que invariablemente es afectado también por todas las eventualidades y replanteamientos que implica la ejecución de una obra.

El conjunto de relaciones circunstanciales relativas al proyecto, en el fondo, hace síntesis con las formas universales, de tal modo que la identidad de la obra y su sentido de pertenencia se materializa en trabajos que surgen de un proceso creativo basado en la puesta en relación de una serie de variables, incluyendo también la voluntad plástica del autor. Algo similar seńala Francisco Bullrich cuando pone en duda la manera rígida y preconcebida con que operan ciertos sectores en la búsqueda de lo propio. Para Bullrich, lo nacional en el arte no es algo que pueda detectarse fuera de las obras de los artistas, "sino que justamente es una realidad que surge con ellos, adquiere consistencia solo a través de sus obras y, por otra parte, obtiene reconocimiento universal en la medida en que, al superar la simple instancia local, se dirige a una conciencia universal" (Bullrich, 1969, p. 16). Según estas palabras, pareciera que el sentido de lo propio o de la identificación de una cultura con una obra de arquitectura obedece a un proceso más espontáneo que premeditado. Considerando la profusa variedad de realidades latinoamericanas y lo cambiante de ellas, Horacio Torrent seńala que "parece no haber cabida siquiera para la pregunta sobre si la arquitectura puede representar una condición propiamente latinoamericana"; y enseguida agrega: "Los que parecen latentes en América Latina son, ni más ni menos, los grandes problemas de la cultura arquitectónica universal en su condición actual, que toman cuerpo de una manera particular en esta región del planeta" (Torrent, 2015, p. 289). 


\section{LA RELACIÓN EQUILIBRADA (SOL Y SOMBRA)}

La búsqueda de las vanguardias pictóricas pone de relieve un aspecto básico de la forma ligado a su estado de más alta abstracción. Mondrian por ejemplo, el artista neoplástico por antonomasia, declara en 1917 que la pintura moderna -al encontrar la forma y el color por medio de la abstracción- se presenta casi de modo natural como "la imagen exacta de la pura relación" (Mondrian, 1983, p. 16). La pura relación -esas organizaciones básicas de la forma subyacente en el aparente caos de la naturaleza- se halla dominada "por una relación original: la de los extremos opuestos" (Mondrian, 1983, p. 19). Así, la línea horizontal y su opuesta vertical, son para el holandés la relación original irreductible del orden de todas las cosas, en donde su dualidad de posición, perpendicular una respecto de la otra, puede concebirse como "la más equilibrada, por el hecho de que en ésta se manifiesta en armonía total la relación entre los extremos opuestos y, al mismo tiempo, contiene todas las demás relaciones" (Mondrian, 1983, p. 19).

La nueva imagen, además de concreta, es abierta, puesto que admite una multiplicidad de relaciones sin perder su unicidad. Lo general ordenador (verticales y horizontales) y lo particular episódico (desplazamiento de planos de colores) se hacen uno, fenómeno visual que Mondrian designa como "la imagen concreta de la relación equilibrada" (Mondrian, 1983, p. 18), lo que alude asimismo a la conjunción de lo interior (espíritu) y lo exterior (naturaleza).

Años más tarde, en 1956, es Marcel Breuer quien aventura en clave arquitectónica una aproximación convergente. En su texto Sol y Sombra, Breuer propone una visión ecuánime de la materia, la forma y sus relaciones: "El verdadero impacto de cualquier obra reside en su capacidad de unificar ideas contrapuestas, es decir, un punto de vista y su contrario" (Breuer, 2001, p. 130). Y luego añade: "el sol español no se diluye en la sombra. Ambas cosas, en su claridad no diluida, son parte de la misma vida, parte del mismo ideal" (Breuer, 2001, p. 130). El dicho popular "sol y sombra", típico de la tradición taurina espańola, le resulta a Breuer pleno de sentido para ilustrar esa comparecencia de opuestos - tan característica de su obra doméstica americana-, que además de enriquecer la obra de arquitectura, la estabiliza, creando un ámbito espacial donde la aparición de sutilezas, variables y dinamismos prescinde de toda ampulosidad formal.

Desde este atributo básico -aunque exigente- del arte moderno, emana aquel doble compromiso que adquiere la forma para convertirse en arquitectura: universal, en tanto forma que pertenece al mundo y a la especie humana; y circunstancial, en tanto forma perteneciente a un lugar y sus eventualidades. Esta es acaso la misma encrucijada existencial en la que se ha visto envuelto el hombre moderno en su habitar diario, situación que una parte importante de la arquitectura, sobre todo aquella producida hasta los primeros ańos sesenta, se ha encargado de encarnar, curiosamente sin proponérselo demasiado. 


\section{EMPIRISMO CONSTRUCTIVO}

De modo natural, el cambio de paradigma arquitectónico que comporta el advenimiento de la modernidad se patentiza en un comienzo con cierta carencia de teoría y respaldo académico. Tanto en Chile como en la mayoría de los países, la academia clásica mantiene todavía un gran peso. Y es a través de un movimiento reformista de 1933, efectuado al interior de la Escuela de Arquitectura de la Universidad de Chile, que la modernidad comienza a irrumpir en las aulas (Eliash, 1989, p. 36). La incipiente modernidad académica e intelectual, en coexistencia con la enseñanza Beaux Arts, logra imponerse finalmente "con las reformas de 1946 hasta 1952 en las escuelas de arquitectura, la creación de los CIAM chilenos en 1946, la publicación Arquitectura y Construcción” (Eliash, 1989, p. 40). De manera paralela a estos acontecimientos, la elementalidad, la claridad y una mayor agilidad constructiva, propia de los nuevos materiales industriales, llevan a que la arquitectura moderna normalice un tipo de reflexión empírica que se nutre básicamente del propio hacer y de la observación del hacer de los demás. El rol clave de las revistas, como portadoras de nuevos referentes, llega a jugar un papel formativo en tanto que enseñan visualmente la configuración de obras ejemplares, cuyos modelos y soluciones muestran la viabilidad de ser adaptables a las condiciones particulares de cualquier parte del mundo.

Esta intensificación del hecho arquitectónico redunda en un grupo de obras notables en diversas naciones, cuyo "aporte en términos arquitectónicos es mucho mayor y más importante que su posible funcionalización ideológica” (Torrent, 2015, p. 284). La general ausencia de una postura discursiva marcada, quita el velo conceptual y da pie a una valoración más directa de los hechos, aspecto que estrecha el vínculo entre la obra y su correspondiente problemática concreta.

Las obras presentadas a continuación manifiestan en mayor o menor medida las generatrices formales mencionadas hasta ahora, y suponen al mismo tiempo una manera de abordar el proyecto de arquitectura que a la sazón logra un estado de normalidad, aceptación y dominio por parte la mayoría de los profesionales, tanto anónimos como de renombre. Los casos seleccionados configuran un abanico de usos desplegados en la Región de Maule, delineando una secuencia que comprende un conjunto de viviendas, que cuentan con equipamiento público asociado, y un edificio de equipamiento público y privado.

El renovado interés por estas obras, y por varias de sus cualidades arquitectónicas, es fruto de los trabajos realizados desde el año 2014 con los alumnos del curso de Investigación de la Escuela de Arquitectura de la Universidad de Talca. 


\section{DIALÉCTICA 1: EDIFICIO EMPART DE TALCA, 1954-1959}

En un contexto nacional en donde predomina una "acción pública masiva", en Talca "se produce una creciente acción estatal en vivienda social que poco a poco comienza a cambiar la imagen de la ciudad" (González, 1992, p. 34). Así surge, por medio de la acción coordinada entre el Estado y el Departamento Técnico de la Caja de Previsión de Empleados Particulares, este conjunto habitacional que apuesta por contribuir a la ciudad con un paso cubierto, público, que une las calles 1 y 2 Norte (Fig. 1). El pasaje urbano, que se desarrolla bajo un largo volumen de viviendas de tres plantas de altura, trae a la memoria los modelos de viviendas y de ciudad elaborados por Le Corbusier durante la primera mitad del siglo XX, como los proyectados a gran escala en la Ville Radieuse de 1935 y el construido a nivel de suelo del bloque de la Unité d'habitation de Marsella, entre los años 1947 y 1952. En función de la coyuntura que le da origen, el Edificio Empart se adecua a su demanda habitacional y a las características alargadas del predio, mediante un despliegue de bloques mucho más comedido que los desarrollados por el suizo-francés, en donde la carencia de ascensor y su consiguiente limitación de altura es también un factor a considerar. La universalidad de dichos modelos, en su traspaso al caso talquino, pierde literalidad, ganando en cambio en singularidad: a partir de la combinatoria de algunas de las tipologías de bloques alargados también corbuserianos (rediente, peine, cruciforme) se crea una peculiar estructuración del emplazamiento a modo de columna vertebral, desde la cual se descuelgan lateralmente y de forma alternada bloques más compactos que acotan patios de uso público (Fig. 2). La incidencia solar en el predio es decisiva en el resultado final de este esquema, obteniéndose así gran parte de los departamentos con asoleamiento en sus fachadas este y oeste, y una menor cantidad de ellos con exposición directa hacia el norte.

La permeabilidad en planta baja y aquella búsqueda de generosidad espacial del edificio respecto de su entorno inmediato, habitual en la arquitectura de esos ańos, queda reglada por un sistema métrico que se manifiesta subyacente y materialmente entre los pilares exentos de sección circular y un archipiélago de departamentos desplazados unos de otros. El cruce entre orden general (sistema) y variaciones (desplazamientos) confirma en el edificio talquino la validez de una aproximación neoplástica a este tipo de proyecto, mucho menos en su sentido literal pictórico que en su concepción profunda, es decir, como configuración equilibrada que unifica la estabilidad de la forma con una dinámica de sus relaciones. 


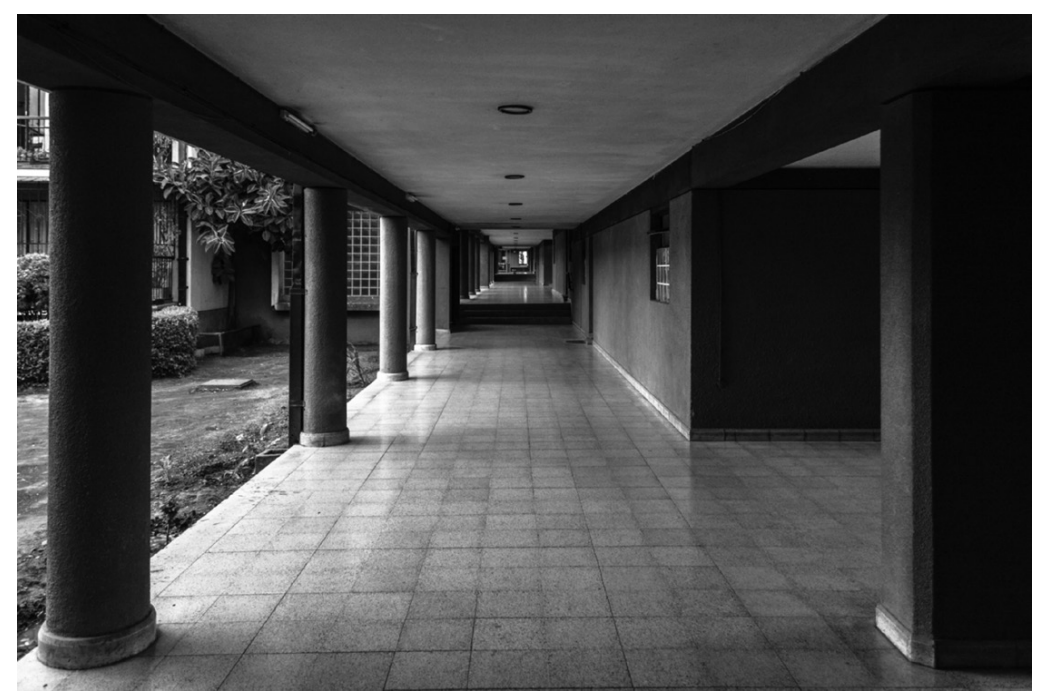

Figura 1: Edificio Empart Talca (C) Diego Carvallo.

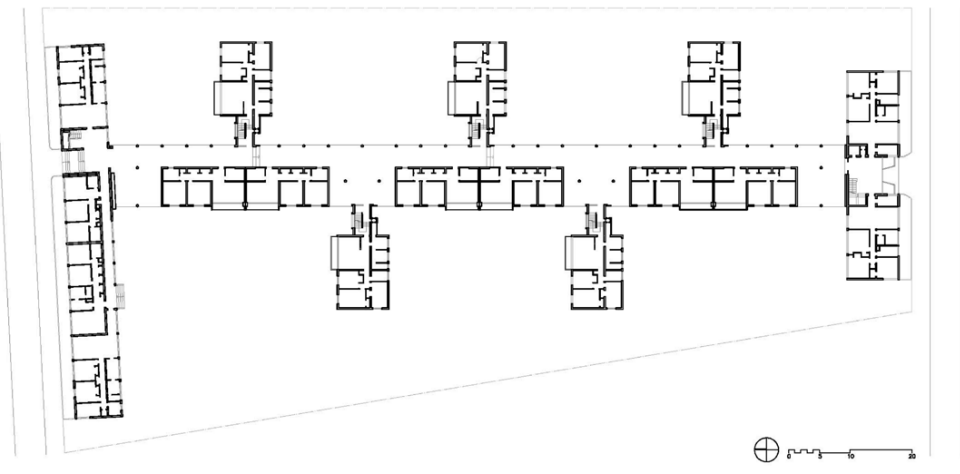

Figura 2: Planta baja Edificio Empart Talca (Dibujo: Marcelo Zúñiga y Nathalie Guerrero).

\section{DIALÉCTICA 2: EDIFICIO CORVI DE TALCA, 1964}

En un contexto similar al del caso anterior, en donde "las ideas renovadoras terminaron imponiéndose cuando fueron asimiladas por la arquitectura estatal" (Eliash, 1989, p. 120), aparece este edificio regional representativo de la Corporación de la Vivienda, responsable por esos años de la construcción del " $60 \%$ del total de viviendas edificadas en el país" (González, 1992, p. 35).

Proyectado por el arquitecto local Pedro Barros Donoso, el edificio ubicado en la céntrica esquina de las calles 2 Norte y 2 Oriente, alberga tanto viviendas en altura como las oficinas administrativas de su entidad responsable, destacando en su concepción formal una recurrencia consciente o inconsciente a la referencia del tipo "placa-torre", estrenado en Nueva York en el año 1951 
con la construcción de la Lever House, a cargo del estudio SOM. Esta tipología, muy extendida por entonces en diversas ciudades del mundo, al momento de la construcción del edificio maulino ya cuenta con dos ejemplares en la capital de nuestro país: el Edificio Plaza de Armas, de 1955, obra de Sergio Larraín, Emilio Duhart, Jaime Sanfuentes, Jaime Larraín y Osvaldo Larraín; y el Edificio Arturo Prat, de 1956, obra de Sergio Larraín y Emilio Duhart. Se podría decir que tales referencias extranjeras y nacionales operan aquí en términos más aparentes que reales: el cuerpo bajo como placa horizontal no es tal; se trata, más bien, de un edificio alargado, como una barra (Fig. 3) que se retira del plomo de la fachada para dejar a los dos bloques de viviendas en una situación visualmente flotante (Fig. 4). Esta sensación de los edificios modernos en su relación con el nivel de suelo público, tiene una serie de precedentes que nos hacen llegar hasta los edificios en altura que construyera Mies van der Rohe en Norteamérica, en especial la Torre Seagram de Nueva York (1954-1958). Sus gruesos pilares cuadrados perimetrales e internos -divididos entre sí tan solo por un tabique de acero y vidrio- participan directamente de la recalcitrante urbanidad de Manhattan. En esta misma línea se encuentran algunas viviendas construidas por Le Corbusier a finales de la década del veinte, sirviéndonos para esta comparación las dos casas pareadas de la Colonia Weissenhof de Stuttgart (1927). El alargado prisma del segundo nivel de viviendas se apoya, en su lado expuesto hacia la calle, sobre una secuencia de pilares compuestos por pares de perfiles de acero de sección rectangular. Con similitudes con el principio general de estas dos obras icónicas, pero con diferencias en cuanto a sus resoluciones en concreto, se manifiesta la parte baja del Edificio Corvi de Talca: la cadencia de los delgados pilares de acero de sección circular, en su independencia del cerramiento, crean un generoso corredor urbano que evoca incluso aquellos tan típicos de la arquitectura hacendal de la Región (Fig. 5). El cruce de influencias no es de extrañar si se toma en cuenta la singularidad del autor: Pedro Barros Donoso pasa en ese tiempo por un proceso de maduración de la modernidad después de un inicio de carrera claramente neoclásico, tal como lo demuestra su primera propuesta para la Municipalidad de Talca del año 1961. 


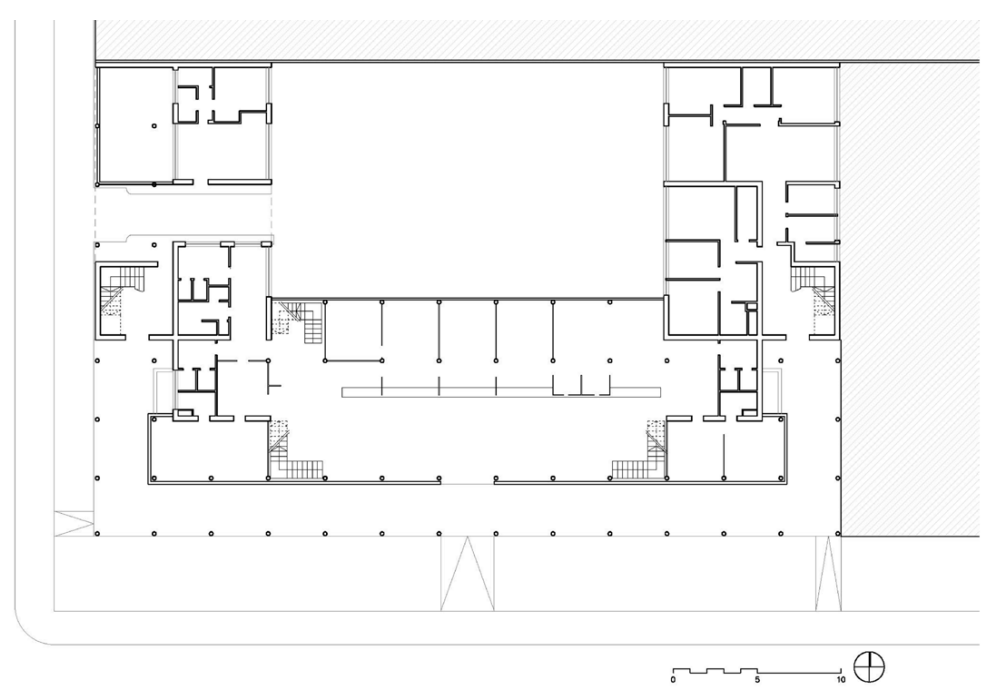

Figura 3: Planta baja Edificio Corvi (Dibujo: Mariela Barrios).

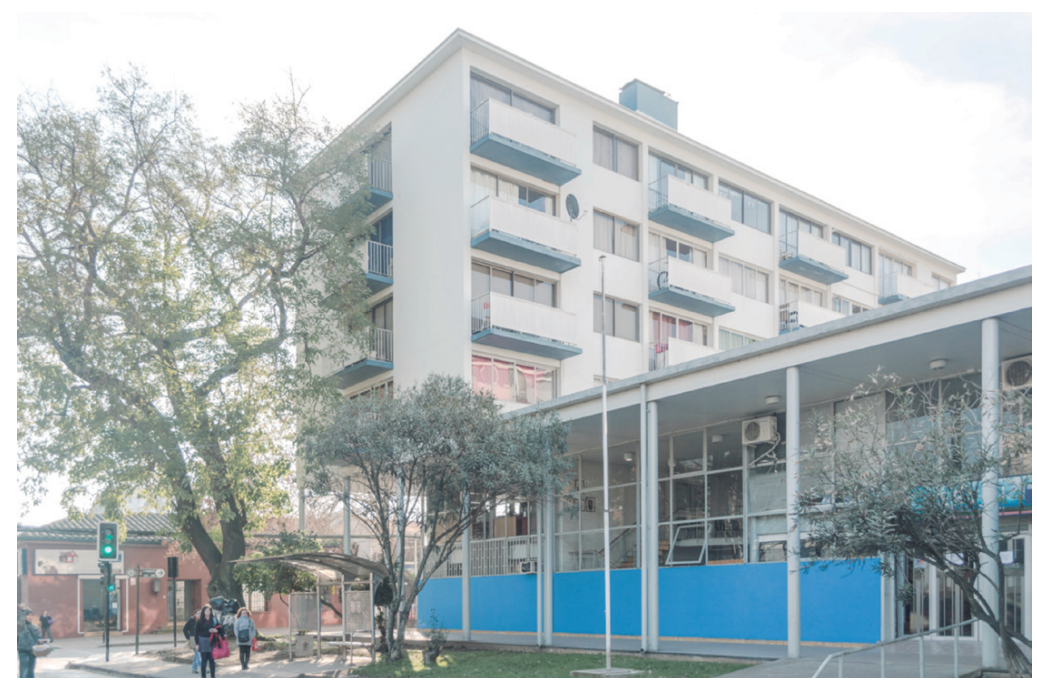

Figura 4: Edificio Corvi de Talca (C Diego Carvallo. 


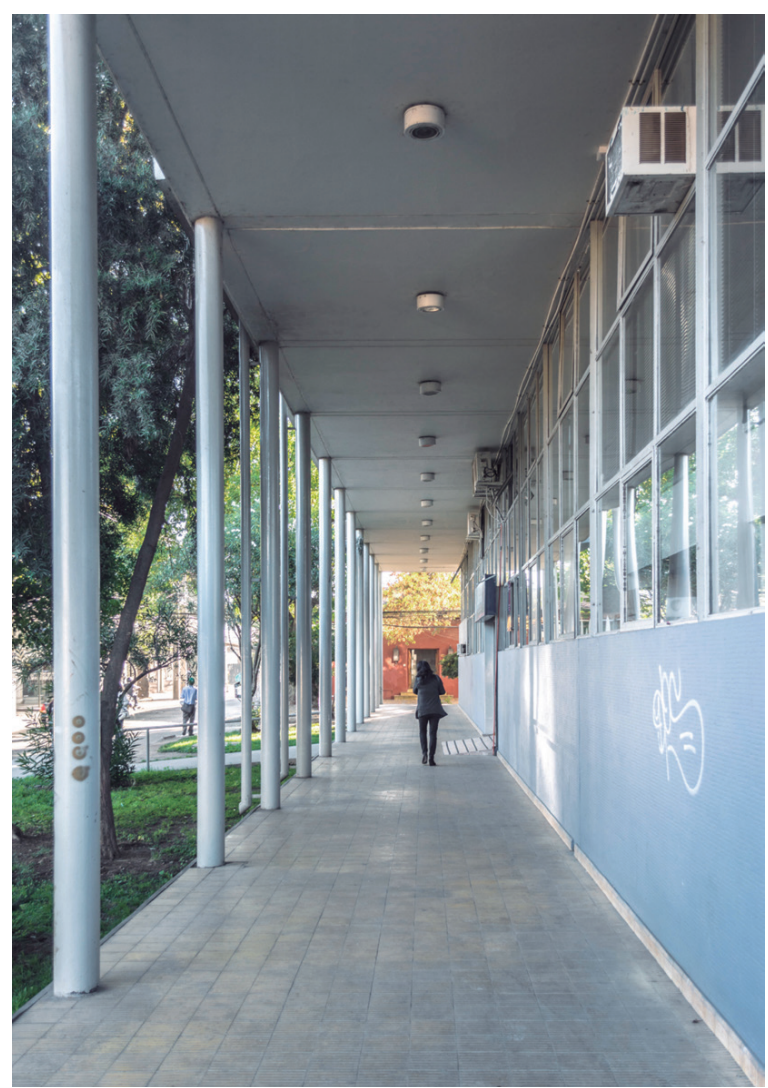

Figura 5: Edificio Corvi de Talca (c) Diego Carvallo.

\section{DIALÉCTICA 3: HOTEL TURISMO LINARES, LINARES, 1960}

Como parte de la cadena Hotelera Nacional S.A. (Honsa), esta obra proyectada por el arquitecto Jorge del Campo, socio hasta el año 1951 de Carlos Bresciani (Pérez, 2006, p. 137), se hace cargo de la ocupación de una esquina protagónica de la Plaza de Armas de Linares. Por medio de un bloque alargado, propone una intensa interacción entre el edificio y la ciudad: el volumen deja tres de sus cuatro fachadas libres, lo que repercute en planta baja en la conformación de una pequeńa plaza interior que se informa programáticamente de una isla de locales comerciales, que a su vez permite el paso libre de los ciudadanos por entre la estructura y los espacios que la edificación ofrece (Fig. 6). De este modo se invierte la usual condición convexa de la esquina por una experimentación cóncava de este tipo de articulación urbana y, con ello, de una profundidad espacial que se acrecienta con la manifestación física y en distintos planos del módulo y el submódulo estructural.

La sesión de un espacio público de calidad a través de las oquedades que deja el edificio, obedece en parte a una tendencia generalizada de la época, destacando en este sentido la construcción entre los años 1954 y 1964 de la Villa Portales en la comuna de 
Quinta Normal. Considerado como uno de los conjuntos habitacionales más logrados hasta el momento en Latinoamérica (Bullrich, 1969, p. 70), tal conjunto realizado por los arquitectos Carlos Bresciani (el anterior socio de Jorge del Campo), Héctor Valdés, Fernando Castillo y Carlos Huidobro, concentra sus méritos en las interrelaciones de una serie de bloques alargados con un extenso predio de 31 ha, cuyas vías peatonales elevadas penetran los volúmenes a su paso por ellos, llegando incluso a posibilitar mediante rampas el ingreso de vehículos hasta el tercer nivel de las edificaciones. Cabe mencionar que el origen de esta búsqueda de asimilación de los pulsos de la ciudad en el edificio de viviendas en altura se gesta fundamentalmente con la construcción, entre los años 1947 y 1952, de la Unité d'Habitation de Marseille por parte de Le Corbusier, que además de conseguir una vasta permeabilidad en planta baja y una azotea concebida como plaza, constituye a media altura del bloque una calle interior que alberga los servicios comunes de aprovisionamiento.

La incidencia del sol sobre el predio ha influido en el desprendimiento del volumen respecto del medianero oriente, ampliando así la superficie de fachadas soleadas al mismo tiempo que ofrece al huésped del hotel vistas interesantes sobre el escenario cívico que ocurre abajo, en la pequeña plaza comercial (Fig. 7). Otra cosa distinta ocurre hacia la cara poniente: conservando la misma pauta métrica de todo el edificio, las aberturas de piso a cielo manifiestan hacia el exterior el claro subrayado horizontal de los cantos de las losas entre los que se deslizan una serie de paneles de celosías móviles (Fig. 8). Estos elementos de cerramiento propios del repertorio constructivo norteamericano (Eliash, 1989, p. 76), incorporados también en el Edificio Plaza de Armas y en la Villa Portales, adquieren en el caso linarense una connotación propia, en tanto que en consonancia con el resto de elementos devienen en la cristalización de un universo material único e irrepetible.

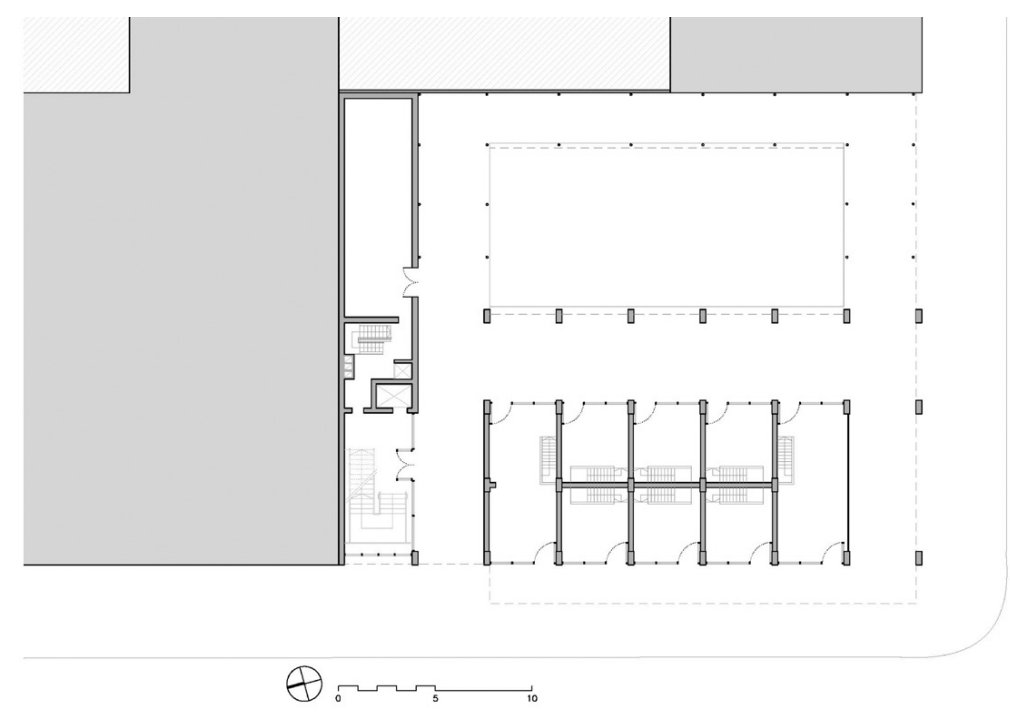

Figura 6: Planta baja Edificio Hotel Turismo Linares (Dibujo: César Ramos y Carolina Fajardo). 


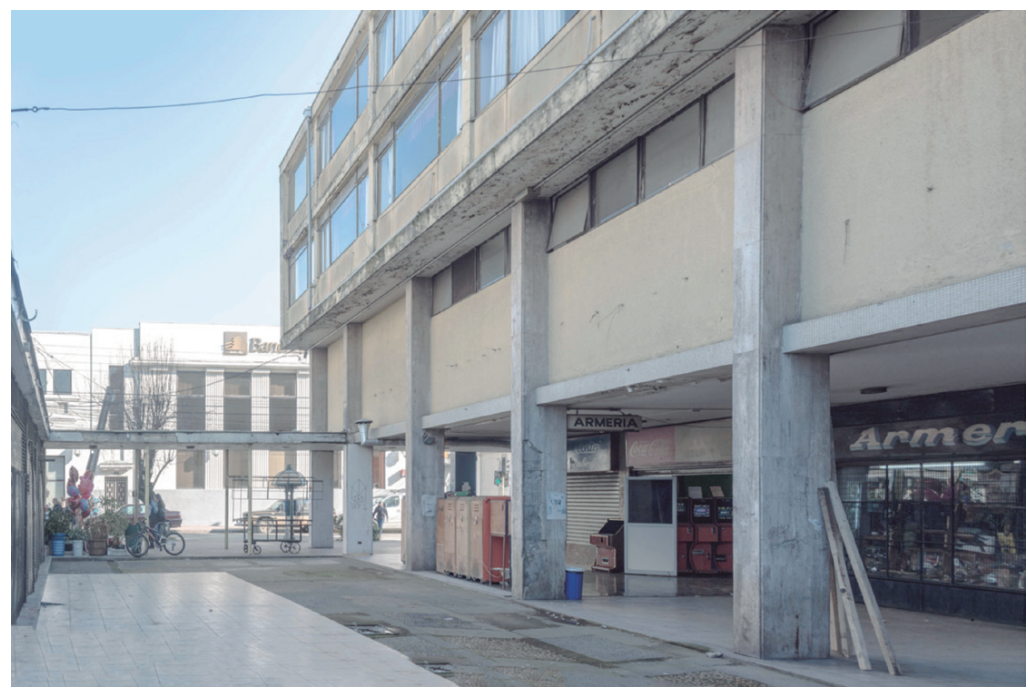

Figura 7: Hotel Turismo Linares visto desde la plaza interior (c) Diego Carvallo.

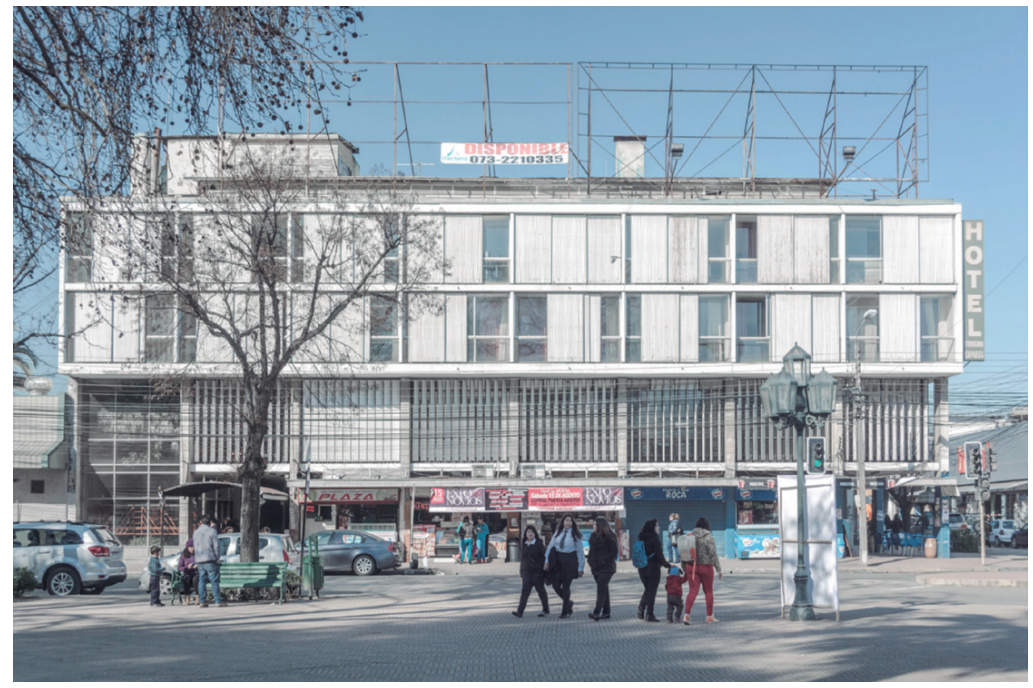

Figura 8: Hotel Turismo Linares visto desde la Plaza de Armas (C) Diego Carvallo.

\section{ARQUITECTURA O EL ARTE DE CONSTRUIR}

Tanto Le Corbusier como Mies van der Rohe $-\mathrm{y}$ sobre todo este último (Neumeyer, 2000, p. 29)- reemplazaron en numerosas ocasiones la palabra "arquitectura" por la expresión "arte de construir". Considerando la dimensión de sus obras, se diría que esta compacta frase apunta a una comprensión de la construcción en el sentido más amplio del término, ligado a esa capacidad intrínseca de la forma de construir relaciones.

De este modo, la profundidad del sentido de construcción en la arquitectura moderna lo impregna todo, desde el universo de relaciones internas de la obra 
(sistema estructural, encuentro de materiales, organización funcional, etc.) hasta el universo de relaciones externas de la misma (entorno inmediato, asociaciones históricas, incidencia social, etc.) Visto así, incluso el encuentro de un pilar con una viga es entendible como una relación, un asunto técnico evaluado visualmente, que incide a su vez en toda una vertebración de vínculos mayores, que terminan por caracterizar a la obra y por condicionar su entrelazamiento con el medio. Esta agudización moderna de lo constructivo como relación -como pura relación, si recordamos a Mondrian- trae consigo el fortalecimiento de la configuración interna de la obra, como urdimbre formal que se equilibra con su contexto a partir de una inercia que va desde adentro hacia afuera.

Es el caso de las tres obras expuestas, la palabra "edificio" se ha hecho limitada para nombrar lo que en realidad corresponde a dialécticas formales, realidades materiales y espaciales que transitan entre una atávica universalidad y sus circunstancias más relativas.

\section{REFERENCIAS}

Breuer, Marcel. “Sol y Sombra”. Revista 2G, 01/17 (2011): 130-131.

Bullrich, Francisco. Arquitectura latinoamericana 1930-1970. Buenos Aires: Editorial Sudamericana, 1969.

Eliash, Humberto; Moreno, Manuel. Arquitectura y modernidad en Chile / 19251965. Una realidad múltiple. Santiago: Ediciones Universidad Católica de Chile, 1989.

Frampton, Kenneth. Historia critica de la arquitectura moderna. Barcelona: Editorial Gustavo Gili, 2014.

Giedion, Sigfried. Espacio, tiempo y arquitectura. Origen y desarrollo de una nueva tradición. Barcelona: Reverté, 2009.

González, Isabel y Colom, Jaime. Talca, la muy noble y muy leal. Talca: Ediciones Universidad Católica del Maule, 1992.

Mondrian, Piet. La nueva imagen en la pintura. Murcia: Colegio oficial de aparejadores y arquitectos técnicos de la región de Murcia, 1983. 
Neumeyer, Fritz. La palabra sin artificio. Reflexiones sobre arquitectura 1922-1968. Madrid: El Croquis Editorial, 2000.

Norberg-Shulz, Christian. Los principios de la arquitectura moderna. Barcelona: Reverté, 2005.

Ozenfant, Amédée; Le Corbusier. Acerca del purismo. Escritos 1918-1926. Madrid: El Croquis Editorial, 1994.

Pérez, Fernando. Bresciani Valdés Castillo Huidobro. Santiago de Chile: Ediciones ARQ, 2006.

Piñón, Helio. Teoría del proyecto. Barcelona: UPC, 2006.

Torrent, Horacio. "Cristal opaco. La arquitectura latinoamericana como categoría historiográfica”. En Hugo Mondragón (ed.). Sudamérica moderna. Objetosedificios-territorios. Hugo Mondragón (ed.). Santiago de Chile: Ediciones ARQ, (2015): 276-291. 